\title{
Plasma Arginine Vasopressin in Diabetic Ketoacidosis
}

\author{
C. H. Walsh ${ }^{1}$, P. H. Baylis ${ }^{2}$, and J. M. Malins ${ }^{1}$ \\ ${ }^{1}$ The Diabetic Unit, General Hospital, and ${ }^{2}$ Department of Medicine, Queen Elizabeth Hospital, Birmingham, England
}

Summary. Plasma Arginine Vasopressin (AVP) was measured serially in 10 patients during the first 24 hours of treatment of diabetic ketoacidosis. AVP was elevated in all cases initially, ranging from $4.0-122.0 \mathrm{pmol} / 1$, the basal level in healthy hydrated subjects being $1.57 \pm 0.59 \mathrm{pmol} / \mathrm{l}( \pm 1 \mathrm{SD})$. The levels fell progressively during the course of treatment. While there was no evidence that the massive increases in AVP noted in this study were associated with water overload it remains to be determined whether the high levels observed have any significant metabolic or haemodynamic role in this disorder.

Key words: Arginine vasopressin, diabetic ketoacidosis, osmolality, volume depletion.

Dehydration is a major feature of patients with diabetic ketoacidosis and is due largely to the osmotic diuresis associated with glycosuria. However, a number of factors other than solute excretion may influence urinary volume, one of the most important being vasopressin, which conserves body water by increasing reabsorption of fluid in the distal renal tubules. Any disturbance of vasopressin secretion, or insensitivity of the kidney to its action, could thus be of serious consequence in patients with diabetic ketoacidosis.

There are a number of reasons for questioning whether impaired vasopressin secretion or activity occur in some patients with ketoacidosis: (1) infusions of hypertonic glucose have been shown to suppress plasma AVP [1]; (2) diabetes insipidus has been reported by some workers to have occurred in patients during the course of ketoacidosis [2,3]; (3) animal studies indicate that in states of acute metabolic acidosis, or potassium depletion, the antidiuretic activity of vasopressin becomes impaired [4]; and (4) it has been suggested that inappropriate AVP secretion may have contributed to the occurrence of cerebral oedema in a patient suffering from diabetic ketoacidosis [5].

In a preliminary study we found elevated levels of AVP in patients suffering from diabetic ketoacidosis [6]. We now present detailed results of a study in which plasma AVP levels have been measured both before and during treatment of ketoacidosis and discuss the clinical relevance of the findings.

\section{Patients}

Ten unselected patients with diabetic ketoacidosis (bicarbonate $<17.0 \mathrm{mmol} / 1$, ketonuria +++ ) were investigated (Table 1 ). There were nine females and one male with ages ranging from 16-68 years (mean 47 years). Two patients were previously undiagnosed diabetics, while in the remaining cases, diabetes had been present for eight years or longer. One patient (Case 5) was on anovulatory agents. In seven patients an infection appeared to be the precipitating factor (chest infection, 2 cases; urinary tract infection, 2 cases; coryzal illness, 2 cases; influenza, 1 case), while there was no apparent precipitating factor in the remaining three cases. Three patients suffered from repeated nausea and vomiting, both before and shortly after admission, while in three other cases, nausea and vomiting had occurred prior to admission only. Abdominal pain was present in two patients (Cases 1 and 4) on admission.

In all patients, treatment of ketoacidosis consisted of hourly low dose insulin by intramuscular injection (a loading dose of Actrapid 12 u IM followed by $6 \mathrm{u}$ IM hourly until the blood glucose level reached $14.0 \mathrm{mmol} / \mathrm{l}$ ), fluid replacement with $0.154 \mathrm{mmol} / \mathrm{l}$ saline initially followed by dextrose infusion $(50 \mathrm{~g} / \mathrm{l})$ when the blood sugar had fallen to $14.0 \mathrm{mmol} / 1$. Potassium supplements (20-30 mmol per litre of fluid) were given in all cases. Bicarbonate was given in two cases. In all patients blood was withdrawn immediately before administration of insulin or fluid (time 0) for measurements of AVP, plasma osmolality, blood glucose, urea and electrolytes, $\mathrm{pH}$ and plasma bicarbonate. These same measurements were repeated in all cases at 6,12 and 24 hours after treatment had commenced. In each patient all urine was 
Table 1. Details of individual patients before treatment. Blood urea levels ranged from $3.4 \mathrm{mmol} / \mathrm{l}$ to $18.6 \mathrm{mmol} / \mathrm{l}(\mathrm{mean} 12.0 \mathrm{mmol} / \mathrm{l})$

\begin{tabular}{|c|c|c|c|c|c|c|c|}
\hline Case & $\begin{array}{l}\text { Age } \\
\text { (years) }\end{array}$ & $\begin{array}{l}\text { Blood glucose } \\
(\mathrm{mmol} / \mathrm{l})\end{array}$ & $\begin{array}{l}\text { Bicarbonate } \\
(\mathrm{mmol} / \mathrm{l})\end{array}$ & $\begin{array}{l}\text { Serum } \mathrm{Na}+ \\
(\mathrm{mmol} / \mathrm{l})\end{array}$ & $\begin{array}{l}\text { B. P. } \\
(\mathrm{mm} \mathrm{Hg})\end{array}$ & $\begin{array}{l}\text { Fluid adminis- } \\
\text { tration } \\
\text { (1/24 hours) }\end{array}$ & $\begin{array}{l}\text { AVP } \\
(\mathrm{pmol} / 1)\end{array}$ \\
\hline 1 & 64 & 55.0 & 5.0 & 133 & $110 / 60$ & 7.3 & $25.4^{\mathrm{a}}$ \\
\hline 2 & 39 & 23.0 & 7.0 & 132 & $150 / 80$ & 6.35 & $83.0^{\mathrm{b}}$ \\
\hline 3 & 16 & 25.0 & 4.0 & 135 & $100 / 70$ & 7.8 & $53.6^{\mathrm{a}}$ \\
\hline 4 & 63 & 52.0 & 6.0 & 138 & $90 / 50$ & 6.7 & $112.0^{\mathrm{b}}$ \\
\hline 5 & 23 & 22.0 & 16.5 & 134 & $120 / 90$ & 5.5 & 4.0 \\
\hline 6 & 88 & 47.0 & 12.0 & 120 & $106 / 60$ & 8.65 & 22.9 \\
\hline 7 & 59 & 50.0 & 11.0 & 153 & $80 / 60$ & 5.6 & 17.9 \\
\hline 8 & 36 & 16.4 & 7.0 & 141 & $90 / 60$ & 8.85 & $67.0^{\mathrm{a}}$ \\
\hline 9 & 41 & 45.5 & 8.0 & 134 & $100 / 65$ & 8.05 & $122.0^{\mathrm{b}}$ \\
\hline 10 & 33 & 25.0 & 12.0 & 136 & $120 / 80$ & 8.0 & 18.6 \\
\hline
\end{tabular}

a Patients in whom vomiting occurred before admission

${ }^{b}$ Patients in whom vomiting occurred both before and following admission

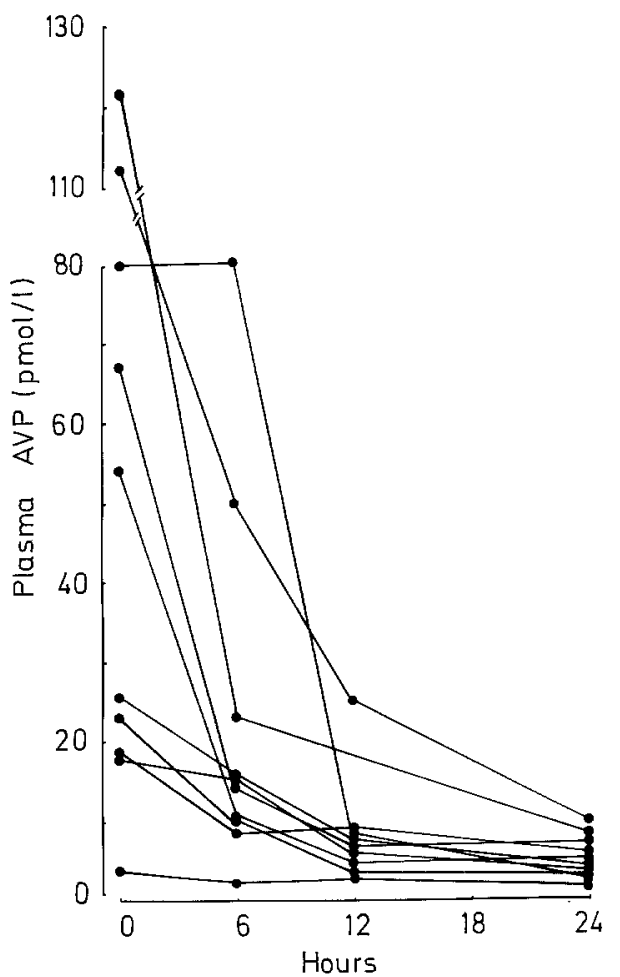

Fig. 1. Changes in AVP during the first 24 hours of treatment in ten patients with diabetic ketoacidosis

collected during the periods $0-6$ hours, 6-12 hours and 12-24 hours, for measurement of volume. Urine osmolality was measured in most cases. Blood sugar was measured on the autoanalyser, using a modification of the ferricyanide method of Hoffman [7]. Blood urea and electrolytes were measured on the autoanalyser by standard techniques. Plasma and urine osmolality were measured by the freezing point method (Osmette Precision Inst. Inc.). Venous blood for AVP measurement was placed in a heparinized tube and centrifuged immediately at $4{ }^{\circ} \mathrm{C}$. Five $\mathrm{ml}$ of plasma was then stored at $20^{\circ} \mathrm{C}$ until assayed within one week, using a radioimmunoassay method previously described [8]. The limit of detec- tion of plasma AVP in this assay is $0.3 \mathrm{pmol} / \mathrm{l}$ and the basal plasma AVP in healthy hydrated subjects of both sexes (age range 19-48 years $)$ is $1.57 \pm 0.59 \mathrm{pmol} / 1( \pm 1 \mathrm{SD})$.

\section{Results}

In all cases, plasma AVP was elevated at the time of admission (Table 1) although the degree of elevation varied widely among individuals. During intensive treatment of the ketoacidosis plasma AVP fell progressively (Figure 1) though by 24 hours the values were still above the normal range in all cases.

Plasma osmolality was elevated before treatment in all patients (Table 2). As in the case of plasma AVP there was marked individual variation. After 24 hours of treatment plasma osmolality had fallen to less than $290 \mathrm{~m} \mathrm{Osmol} / \mathrm{kg}$ in seven of the ten patients. No significant correlation was observed between the initial plasma AVP and plasma osmolality, nor was the correlation between plasma AVP and plasma osmolality significant after either 6,12 or 24 hours of treatment. Furthermore, the initial plasma AVP did not correlate significantly with either the initial blood glucose, serum sodium, $\mathrm{H}+$ or fluid retention over the 24-hour period of treatment.

\section{Discussion}

It is clear from this study that defective AVP secretion is not a feature of diabetic ketoacidosis. In all cases the urine osmolality was higher than that of the plasma, suggesting that the renal tubules were responsive to the action of AVP. However, it is apparent that urinary osmolality levels were in most cases nowhere near the levels found in normal sub- 
Table 2. Gives details of the fluid balance and plasma and urinary osmolalities in the ten patients

\begin{tabular}{|c|c|c|c|c|c|c|c|}
\hline \multirow[t]{2}{*}{ Case } & \multicolumn{2}{|c|}{ Plasma osmolality (m Osmol/kg) } & \multirow{2}{*}{$\begin{array}{l}\text { Fluid adminis- } \\
\text { tration in first } \\
24 \text { hours [1] }\end{array}$} & \multirow{2}{*}{$\begin{array}{l}\text { Fluid retained in } \\
\text { first } 24 \text { hours [1] }\end{array}$} & \multicolumn{3}{|c|}{ Urine osmolality (m Osmol/kg) } \\
\hline & 0 & $24 \mathrm{hrs}$ & & & $0-6$ hrs & $6-12 \mathrm{hrs}$ & $12-24 \mathrm{hrs}$ \\
\hline 1 & 379 & 311 & 7.3 & 4.76 & 444 & 613 & 728 \\
\hline 2 & 326 & 283 & 6.35 & 3.0 & 538 & 680 & 462 \\
\hline 3 & 347 & 287 & 7.8 & 3.0 & 568 & 616 & 537 \\
\hline 4 & 340 & 308 & 6.7 & 4.25 & 428 & - & 580 \\
\hline 5 & 299 & 273 & 5.5 & 1.6 & 989 & 490 & 278 \\
\hline 6 & 313 & 286 & 8.65 & 6.0 & 450 & 377 & 437 \\
\hline 7 & 406 & 324 & 5.6 & 4.15 & - & 379 & 324 \\
\hline 8 & 318 & 285 & 8.85 & 6.15 & 621 & - & 447 \\
\hline 9 & 346 & 288 & 8.05 & 4.65 & 542 & - & 492 \\
\hline 10 & 315 & 281 & 8.0 & 6.0 & 605 & - & 433 \\
\hline
\end{tabular}

jects in the presence of maximal antidiuretic activity (about $1200 \mathrm{~m} \mathrm{Osmol} / \mathrm{kg}$ ). It appears therefore that in diabetic ketoacidosis the osmotic diuresis overrides the antidiuretic effect of AVP.

It has been suggested that inappropriate AVP secretion may contribute to the development of cerebral oedema in diabetic ketoacidosis [5]. However, in no patient in this study were features of fluid overload or cerebral oedema observed. Furthermore, since maximal antidiuretic activity of AVP is achieved at levels well below those seen initially in the majority of our patients [9] it seems that the gross elevations found during the early hours of treatment of diabetic ketoacidosis are unlikely to pose a hazard in terms of water intoxication. However AVP levels are still elevated 24 hours after starting treatment, by which time plasma hyperosmolality has been corrected in most patients. Thus care should be taken to avoid hypotonic fluids at this time.

Apart from its antidiuretic action, vasopressin has been shown in animals to exert a hyperglycaemic action [4] and in addition to alter plasma free fatty acid levels (NEFA). However we have found no correlation between plasma AVP and blood sugar levels. Though NEFA have not been measured in this study, no correlation was found between plasma AVP levels and $\mathrm{pH}$.

The cause of the elevated plasma AVP levels merits comment. Both an increase in plasma osmolality and a decrease in blood volume stimulate AVP release, though it appears that changes in osmolality are dominant. In normal subjects a significant correlation exists between plasma osmolality and plasma AVP, an increase of only $1 \%$ in osmolality resulting in a rise in AVP levels [10]. However, no correlation was observed between plasma AVP and either plasma osmolality or volume depletion (measured as fluid replacement) in this study. At least two possible explanations for this apparent discrepancy exist. Firstly, the degree of hyperosmolality in many of our patients was extreme and it seems likely that there exists a cut-off point above which further increases in plasma osmolality have little further effect on AVP secretion. Secondly, the concentrations of AVP found in the majority of these patients are very much higher than those produced by dehydration of normal subjects. Such high concentrations can readily be produced in normal subjects by a variety of nonosmotic mechanisms including vaso-vagal attacks [10]. The induction of nausea and vomiting is also an extremely potent stimulus to AVP secretion [10]. It is thus of interest that the six patients in this study in whom nausea and vomiting occurred were those with the highest AVP levels. Pain which was present in two cases, may also cause an increase in AVP levels [11], as may hyperreninaemia, which occurs in diabetic ketoacidosis [12, 13].

Our observations suggest that in diabetic ketoacidosis several factors may contribute to the elevation of AVP. Though in some cases the levels of this hormone are raised to a massive degree, we have found no evidence that these have a deleterious effect on water metabolism in diabetic ketoacidosis. It is apparent, however, that vasopressin is a hormone with a potentially wide range of actions and it remains to be determined whether such actions are of clinical significance in conditions such as ketoacidosis.

\section{References}

1. Athar, S., Robertson, G. L.: Osmotic control of vasopressin secretion in man. Clin. Res. 22, 335A (1974)

2. Taübin, H., Matz, R.: Cerebral oedema, diabetes insipidus and sudden death during the treatment of diabetic ketoacidosis. Diabetes 17, 108-109 (1968) 
3. FitzGerald, M. G., O'Sullivan, D. J., Malins, J. M.: Fatal diabetic ketosis. Br. Med. J. 1961 I, 247-250

4. Forsling, M.: Annual Research Reviews. Lancaster: A. D. H. Eden Press 1977

5. Duck, S. C., Welton, V. V., Pagliara, A. S., Haymond, M. W.: Cerebral oedema complicating therapy for diabetic ketoacidosis. Diabetes 25, 111-115 (1976)

6. Walsh, C. H., Baylis, P. H., McKendrick, M., Malins, J. M.: A study of plasma arginine vasopressin in diabetic ketoacidosis. Diabetologia 13, 439 (1977)

7. Hoffman, W. S.: A rapid photo electric method for determination of blood glucose in blood and urine. J. Biol. Chem. 120, 51-55 (1937)

8. Baylis, P. H., Heath, D. A.: The development of a radioimmunoassay for the measurements of human plasma arginine vasopressin. Clin. Endocrinol. (Oxf.) 7, 91-102 (1977)

9. Robertson, G. L.: Vasopressin in osmotic regulation in man. Annu. Rev. Med. 25, 315-322 (1974)

10. Robertson, G.L.: The regulation of vasopressin function in health and disease. Recent Prog. Horm. Res. 33, 335-385 (1977)
11. Kendler, K. S., Weitzman, R. E., Fisher, D. A.: The effect of pain on plasma arginine vasopressin concentrations in man. Clin. Endocrinol. (Oxf.) 8, 89-94 (1978)

12. Bonjour, J. P., Malvin, R. L.: Stimulation of ADH release by the renin-angiotensin system. Am. J. Physiol. 218, 1555-1559 (1970)

13. Christlieb, A. T., Assal, J.P., Katsilambros, N., Williams, G. H., Kozak, G.P., Suzuki, T.: Plasma renin activity and blood volume in uncontrolled diabetes. Diabetes 24, 190-193 (1974)

Received: July 10, 1978, and in revised form: September 6, 1978

Dr. C. H. Walsh

International Missionary

Training Hospital

Drogheda

Ireland 